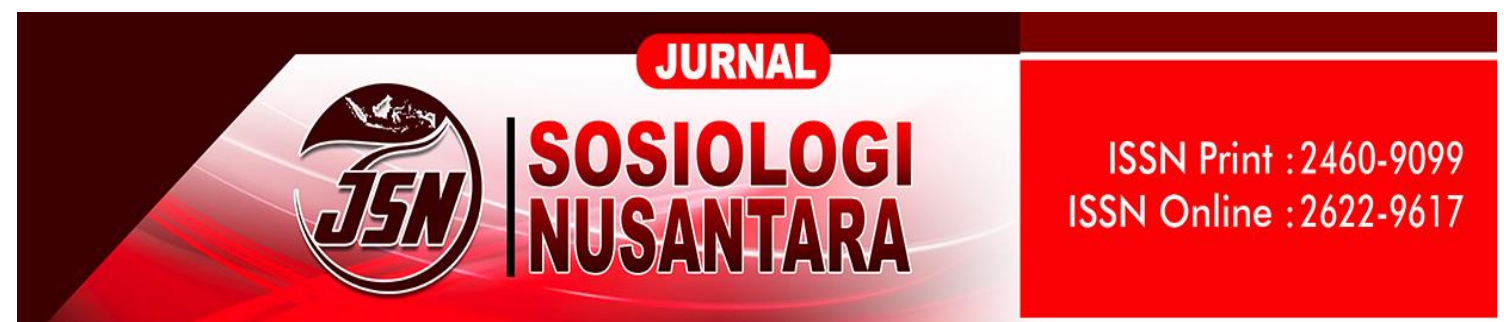

https://ejournal.unib.ac.id/index.php/jsn

DOI ://doi.org/10.33369/jsn.7.2.299-310

\title{
GAYA HIDUP PEREMPUAN KOMUNITAS SENAM AEROBIK (Studi Kasus Pusat Kebugaran CIKTAM Studio Bengkulu)
}

\section{LIFESTYLE OF WOMEN'S AEROBIC GYMING COMMUNITY (Case Study Of Fitness Center CIKTAM Studio Bengkulu)}

\author{
Rina Krismonica1, Panji Suminar ${ }^{2}$, Sumarto Widiono ${ }^{3}$ \\ rinakrismonica841@gmail.com \\ 1,2,3 Universitas Bengkulu
}

\begin{abstract}
Abstrak
Penelitian ini bertujuan untuk mendeskripsikan bagaimana gaya hidup komunitas wanita senam aerobik dan pola hidup sehat wanita peserta senam aerobik di Ciktam Studio Bengkulu Fitness Center Penelitian ini menggunakan pendekatan deskriptif kualitatif dan penentuan informan menggunakan snowball atau bola salju. Pengumpulan data menggunakan teknik observasi, wawancara mendalam terhadap 3 (tiga) orang peserta senam putri, dan dokumentasi. Analisis penelitian ini menggunakan teori Simulakrum dari Jean Baudrilard yang digunakan sebagai pedoman dalam menganalisis. Hasil penelitian ini menjelaskan bahwa gaya hidup peserta senam wanita merupakan gaya hidup masyarakat kelas menengah ke atas yang dapat dilihat melalui aktivitas yang dilakukannya setiap hari mulai dari pergi ke pusat kebugaran aerobik dan berbelanja kebutuhan hidup sehat dan juga berbelanja kebutuhan sehari-hari. atribut senam modis. Sedangkan pola hidup sehat wanita peserta senam aerobik di Ciktam Studio Bengkulu Fitness Center didapatkan bahwa mereka menjalani pola hidup sehat dengan mengkonsumsi makanan dan minuman yang sehat, bergizi dan rendah lemak. Peserta senam aerobik wanita menjalankan pola hidup sehat mulai dari mengatur pola makan yang dimulai dari mengkonsumsi makanan dan minuman yang sehat dengan memperbanyak konsumsi sayur dan buah serta memiliki waktu istirahat yang cukup diimbangi juga dengan olahraga yang teratur karena melalui olahraga yang teratur akan memiliki daya tahan fisik yang baik, sehingga akan memiliki fisik yang fit dan mendukung dalam melakukan aktivitas secara optimal.
\end{abstract}

Kata Kunci: Gaya Hidup. Gaya hidup sehat. Peserta Senam Aerobik Putri. 


\begin{abstract}
This study aims to describe how the lifestyle of women community aerobic gymnastics and healthy lifestyle of women aerobic gymnastics participants at Ciktam Studio Bengkulu Fitness Center This study uses qualitative descriptive approaches and determination of informants using snowball or snowball. Data collection uses observation techniques, in-depth interviews of 3 (three) female gymnastics participants, and documentation. Analysis of this study uses Jean Baudrilard's theory of Simulakrum which is used as a guide to analyzing. The results of this study explained that the lifestyle of women gymnastic participants is the lifestyle of the upper middle class that can be seen through the activities that he does every day from going to aerobic fitness centers and going shopping needs for healthy living and also shopping for fashionable gymnastics attributes. While the healthy lifestyle of women aerobic gymnastics participants at Ciktam Studio Bengkulu Fitness Center found that they lead a healthy lifestyle by consuming healthy, nutritious and low-fat foods and drinks. Women aerobic gymnastics participants run a healthy lifestyle from regulating a diet that starts from consuming healthy foods and drinks by increasing the consumption of vegetables and fruits and having enough rest time balanced also with regular exercise because through regular exercise will have good physical endurance, so it will have a fit and supportive physique in doing optimal activity.
\end{abstract}

Keyword: Lifestyle. Healthy Lifestyle. Female Aerobic Gymnastics Participants.

\title{
PENDAHULUAN
}

Kehidupan masyarakat kota yang sangat menarik dan terus berubah membuat masyarakat kota cenderung berkelompok-kelompok, pengelompokan berdasarkan aktivitas tertentu mewarnai kota dibidang sosial dan ekonomi yang menunjukkan status sebagai pusat-pusat aktivitas yang profesional dan potensi. Masyarakat perkotaan sering diidentikkan dengan masyarakat modern (maju), masyarakat modern adalah masyarakat yang sebagian besar warganya mempunyai orientasi nilai budaya yang terarah ke kehidupan masa kini. Sesuai perkembangan zaman yang menyertainya, masyarakat kota banyak terlibat pada perkumpulan-perkumpulan atau ikatan sukarela, masyarakat kota secara sukarela menggabungkan dirinya pada suatu perkumpulan (organisasi) yang disukainya. Salah satu perkumpulan itu adalah komunitas senam aerobik, senam aerobik menjadi salah satu pilihan bagi masyarakat perkotaan sebagai wadah mengisi aktifitas dalam menunjang gaya hidupnya (Saebani, 2015: 25).

Menurut Irfan (dalam Candrawati, 2016: 70) bagi masyarakat yang maju dan modern kegiatan olahraga sudah menjadi kebutuhan dalam kehidupan sehari-hari. Melalui olahraga, individu dapat mengembangkan segi-segi mental kepribadian, moral, kepemimpinan, kesetiaan, loyalitas, dan pengabdian. Sejalan dengan itu, olahraga senam 
dewasa ini sudah sedemikian maju, khususnya senam aerobik yang sangat diminati ibuibu di perkotaan. Salah satu aktivitas fisik atau olahraga yang saat ini banyak diminati oleh masyarakat adalah senam aerobik, kebutuhan wanita akan bentuk tubuh yang ideal menjadikan senam aerobik sebagai pilihan bentuk latihan fisik yang disukai kaum perempuan karena aspek rekreasionalnya dan dapat digunakan sebagai ajang sosialisasi. Senam aerobik pun dapat dilakukan secara berkelompok dibawah arahan seorang instruktur senam dan diikuti dengan iringan musik populer, gerakan yang ada pada senam aerobik tidak sulit untuk dilakukan karena diciptakan secara sistematis dan terencana sehingga mudah untuk diikuti.

Senada dengan pendapat Viii et Al (dalam Ramadhani, 2019: 5) bahwa senam aerobik adalah aktivitas gerak yang dilakukan oleh perorangan maupun kelompok orang secara berirama, menggunakan otot-otot besar, dengan menggunakan sistem energi aerobik dan mengikuti irama musik yang juga dipilih sehingga melahirkan ketentuan ritmis, kontinuitas, dan durasi tertentu yang bertujuan untuk peningkatan dan pemeliharaan kebugaran tubuh serta tujuan lain misalnya menurunkan berat badan.

Diperjelas kembali oleh Soekarno (dalam Purwanto, 2011: 2) bahwa pada pelaksanaannya senam aerobik menggunakan iringan musik yang berguna untuk meningkatkan motivasi latihan dan kecepatan latihan, dengan demikian intensitas latihan dapat diatur dengan pengaturan tempo musik yang mengiringinya. Senam aerobik merupakan salah satu bentuk latihan aerobik selain bersepeda, renang, jogging, berlari dan permainan seperti bulu tangkis, sepak bola, tenis dan sebagainya. Sekarang ini senam aerobik banyak dipilih masyarakat untuk meningkatkan kebugaran, dalam senam aerobik dipilih gerakan yang mudah, menyenangkan dan bervariasi sehingga memungkinkan seseorang untuk melakukannya secara teratur dalam kurun waktu yang lama.

Berangkat dari latar belakang di atas, penulis mencoba menganalisis yaitu bagaimana gaya hidup perempuan peserta senam aerobik di Pusat Kebugaran Ciktam Studio Bengkulu? dan bagaimana gaya hidup sehat perempuan peserta senam aerobic melalui aktivitas,minat dan opininya.

\section{Gaya Hidup}

Gaya hidup menurut Kotler (dalam Ramadani, 2018: 7) adalah perilaku seseorang yang ditunjukkan dalam aktivitas, minat, opini, khususnya yang berkaitan dengan citra 
diri untuk merefleksikan status sosialnya. Gaya hidup menggambarkan keseluruhan diri seseorang dalam berinteraksi dengan lingkungannya.

Secara sosiologis menurut Featherstone (dalam Hendariningrum, 2008: 26) bahwa gaya hidup (lifestyle) merujuk pada gaya hidup khas suatu kelompok tertentu. Sementara dalam masyarakat modern, gaya hidup (lifestyle) membantu mendefinisikan mengenai sikap, nilai-nilai, kekayaan, serta posisi sosial seseorang (Chaney, 2004). Dalam masyarakat modern istilah ini merupakan ekspresi diri, serta kesadaran diri untuk bergaya. Tubuh, busana, cara bicara, hiburan saat waktu luang, pilihan makanan dan minuman, rumah, kendaraan, bahkan pilihan sumber informasi, dan seterusnya dipandang sebagai indikator dari individualistis selera, serta rasa gaya dari seseorang.

Esensinya di era modern ini, gaya hidup merupakan gambaran bagi setiap orang yang mengenakannya dan menggambarkannya seberapa besar perilaku seseorang didalam masyarakat. Selain itu gaya hidup juga dapat diartikan sebagai suatu seni yang dibudidayakan oleh setiap orang, gaya hidup yang dijalani dapat menentukan kualitas hidup dan kesehatan tubuh. Seseorang yang memiliki gaya hidup yang positif dan pola hidup yang sehat cenderung memiliki kualitas hidup yang lebih memadai begitu juga sebaliknya (Khairunnisa, 2015: 1-6).

\section{Gaya Hidup Sehat}

Sementara menurut Proverati dan Rahmawati bahwa gaya hidup sehat adalah gaya hidup seimbang dengan pola makan, kebiasaan dan lingkungan yang sehat guna mendapatkan fisik yang sehat. Pengaturan jenis makanan penting untuk diperhatikan, seperti konsumsi buah dan sayur lebih banyak dibanding makanan lain guna mencegah peningkatan berat badan. Senada dengan pendapat Sunarno (dalam Prastika, 2019: 36) gaya hidup sehat adalah mengupayakan kebiasaan baik guna menciptakan hidup sehat dan menghindarkan kebiasaan buruk yang dapat mengganggu kesehatan.

Gaya hidup sehat adalah suatu cara bertindak atau berpenampilan yang diatur oleh standar kesehatan tertentu. Gaya hidup sehat mencakup hal-hal seperti memakan makanan dan minuman yang sehat, latihan atau olahraga yang terprogram, melakukan kebiasaan baik dan meninggalkan kebiasan jelek. Serta memperbaiki lingkungan alam atau sekitar, selalu berupaya meningkatkan ilmu pengetahuan terutama tentang kesehatan (life long learning), mengelola waktu, mengelola keuangan, serta interaksi yang harmonis dengan sesama manusia (Kusmaedi, 2012: 325) 
Upaya yang dapat dilakukan dalam penerapan gaya hidup sehat menurut Sunarno (dalam Prastika, 2019: 36) seperti mempertahankan berat badan, mengatur pola dan jenis makan, melakukan olahraga teratur, manajemen stres yang baik, hindari merokok dan minum alkohol, dan memeriksakan kesehatan berkala.

Robbins (dalam Paramitha, 2014: 83) merekomendasikan menerapkan gaya hidup sehat dalam kehidupan sehari-hari melalui olahraga secara rutin dan memiliki waktu istirahat yang cukup, karena dengan berolahraga secara rutin, individu akan memiliki ketahanan fisik yang baik sehingga staminanya juga meningkat, berolahraga juga dapat memberikan sebuah pengalihan dari tekanan kerja dan menawarkan cara untuk melepaskan energi, sasarannya adalah mencapai suatu keadaan relaksasi sehingga kondisi psikologis individu pun dapat menjadi lebih tenang dan berpikir positif. Saat kondisi fisik dan psikologis individu berada dalam kondisi yang baik maka tekanan yang terjadi dapat ditekan, sehingga membuat individu lebih nyaman dan betah dalam menjalani pekerjaannya. Begitu pula dengan adanya asupan makanan sehat yang dianjurkan yaitu dengan mengurangi alkohol dan rokok yang dapat mengancam kesehatan, sehingga saat kondisi tubuh sehat maka kondisi individu tersebut juga lebih bahagia dan lebih tahan terhadap stress.

Menurut Weber, kelas sosial merupakan stratifikasi sosial yang berkaitan dengan hubungan produksi dan penguasaan kekayaan. Sedangkan status sosial merupakan manifestasi dari stratifikasi sosial yang berkaitan dengan prinsip yang dianut oleh komunitas dalam mengkonsumsi kekayaannya atau gaya hidupnya. Kelas sosial merupakan himpunan orang-orang yang memperagakan fungsi yang sama dalam organisasi. Kelas-kelas sosial dalam komunitas dibedakan berdasarkan perbedaan posisinya dalam tatanan ekonomi (Aji, 2015: 6-7).

Menurut Maliki (dalam Triwijayati, 2018: 144) bahwa perempuan kelas menengah atas (upper middle class) mencakup kebanyakan pengusaha dan orang profesional yang berhasil, yang umumnya berlatar belakang keluarga baik dan berpenghasilan yang menyenangkan. Kelas sosial menentukan gaya hidup seseorang, menurut Marx faktor yang paling penting mempengaruhi gaya hidup dan kesadaran individu adalah posisi kelas sosialnya di masyarakat. Kehidupan individu pada kelas sosial akan tercermin dari gaya hidup yang ia bentuk, adapun ciri-ciri kelas sosial adalah orang-orang yang termasuk dalam kelas sosial tertentu kemungkinan bertingkah laku sama, orang dinilai berkedudukan rendah atau berkedudukan tinggi berdasarkan kelas sosial mereka, kelas 
sosial tidak hanya ditentukan oleh variabel tunggal melainkan diukur berdasarkan fungsi jabatan atau pekerjaan, pendapatan, kekayaan, pendidikan, orientasi nilai seseorang dan sebagainya (Arbaini, 2017: 5).

\section{METODE PENELITIAN}

Penelitian gaya hidup perempuan komunitas senam aerobik ini menggunakan metode kualitatif dengan memakai pendekatan deskriptif. Penelitian deskriptif suatu bentuk penelitian yang ditujukan untuk mendeskripsikan fenomena-fenomena yang ada, baik fenomena alamiah maupun fenomena buatan manusia. Fenomena itu bisa berupa bentuk, aktifitas, karakteristik, perubahan, hubungan, kesamaan, dan perbedaan antara fenomena yang satu dengan fenomena lainnya. Penelitian deskriptif merupakan penelitian yang berusaha mendeskripsikan gaya hidup perempuan peserta senam aerobik dan gaya hidup sehat perempuan peserta senam aerobik di pusat kebugaran ciktam studio Bengkulu.

Teknik pengumpulan data yang digunakan dalam penelitian ini antara lain observasi, dokumentasi, dan wawancara. Teknik observasi yang digunakan menggunakan observasi partisipasi aktif. Teknik dokumentasi dalam penelitian ini mengumpulkan data dari dokumen yang sudah ada, sehingga penulis dapat memperoleh catatan-catatan yang berhubungan dengan penelitian. Peneliti mendapatkan gambaran umum pusat kebugaran, keadaan peserta senam aerobik, catatan-catatan dan juga foto yang dapat dijadikan dokumentasi. Teknik wawancara pada penelitian ini menggunakan wawancara tidak terstruktur agar hasil wawancara ini dapat memperjelas hasil data-data yang dilakukan pada saat observasi, dan akan mendapatkan hasil yang lebih akurat serta mendalam terhadap permasalahan tersebut.

Lebih jauh, teknik analisis data dalam penelitian ini mencakup reduksi data, penyajian data, serta penarikan kesimpulan. Berbagai data yang telah terkoleksi melalui observasi, dokumentasi dan wawancara, diklasifikasikan ke dalam beberapa kategori untuk kemudian disajikan dan dianalisis dengan menggunakan teori simulakrum Jeand Baudrillard yang menganalisis masyarakat dengan sistem tanda dan simbol. Dan tahapan terakhir adalah penarikan kesimpulan, dalam tahapan pertama dilakukan penarikan kesimpulan sementara, yakni mempelajari kembali berbagai data awal penelitian serta beragam data baru yang diperoleh. Kedua, data tersebut kemudian diverifikasi dan dianalisis kembali sehingga sampailah pada penarikan kesimpulan. 


\section{PEMBAHASAN}

\section{A. Gaya Hidup Ditunjukkan Dalam Aktivitas, Minat, dan Opini.}

1. Aktivitas di Dalam Rumah

Saat berada di dalam rumah banyak aktivitas yang dapat dilakukan bagi perempuan peserta senam aerobik, dari mulai menyiapkan perlengkapan atau atribut senam seperti pakaian senam yang mampu menyerap keringat saat berlangsungnya senam, selain pakaian senam sepatu olahraga untuk juga disiapkan untuk melakukan senam. Bagi pesenam, rutinitas menyiapkan perlengkapan senam ini setiap hari ia lakukan sebelum besok harinya pelaksanaan senam aerobik. Tidak hanya menyiapkan perlengkapan senam, perempuan peserta senam juga menyibukkan diri dengan memasak ataupun merebus makanan dan minuman sehat untuk kebutuhan dirinya dan keluarganya.

\section{Aktivitas Di Luar Rumah}

Sebagai seorang perempuan pesenam, berbagai aktivitas yang biasa dilakukan saat berada di luar rumah seperti menjaga penampilan yang menjadi tuntutan profesi sebagai perempuan karier. Kebanyakan dari perempuan peserta senam aerobik menghabiskan waktunya di luar rumah dengan berbagai aktivitas. Kebanyakan dari perempuan peserta senam aerobik ini merupakan perempuan karier yang bekerja di bidang publik sehingga membuat profesi ini memiliki citra atau image tersendiri di mata masyarakat. Adanya tuntutan profesi juga ditambah dengan keinginan untuk tampil menarik dan menunjukan status sosial yang didapatkan dari menjalani profesinya sebagai perempuan karier membuat perempuan modern yang bekerja di luar rumah ini untuk berperilaku konsumtif.

Aktivitas perempuan peserta senam aerobik ini ketika diluar rumah selain bekerja, mereka biasa menghabiskan waktu yang dimilikinya dengan belanja barang-barang yang disukainya tanpa memikirkan nominal, aktivitas belanja ini rutin dilakukannya untuk membeli barang-barang yang disukainya untuk menunjang penampilannya. Ia kerap kali berbelanja barang-barang seperti baju, sepatu dan barang lainnya yang mempunyai kelas dan bermerek.

\section{Bergabung Pada Komunitas Senam Aerobik (Minat)}

Komunitas Senam aerobik merupakan perkumpulan, dimana anggotanya akan merasakan manfaat dan nilai lebih dari senam aerobik itu sendiri. Bergabung pada komunitas senam aerobik menurut peserta senam aerobik yang menjadi anggota atau 
peserta senam pusat kebugaran merupakan keinginan mereka sendiri. Senam aerobik menjadi tempat berinteraksi dan sumber informasi bagi peserta senam aerobik.

Pesenam Merupakan Perempuan Modern (Opini) Menjadi bagian dari perempuan masa kini tentu saja membuat pesenam punya pemikiran yang sedikit berbeda. Zaman yang semakin modern membuat perempuan kini memiliki banyak ruang untuk menunjukkan dirinya. Menjadi bagian dari perempuan masa kini tentu saja membuat mereka punya pemikiran yang sedikit berbeda. Apalagi untuk menunjukkan sisi diri yang smart dan stylish. Bagi perempuan modern, menjadi smart dan stylish artinya percaya dengan diri mereka sendiri. Termasuk soal pandangan cantik, perempuan peserta senam tidak dipusingkan dengan standar kecantikan. Dari pada memikirkan kekurangan diri, mereka justru fokus untuk mengenali kelebihannya dan menjadi cantik dengan caranya sendiri

\section{B. Gaya Hidup Sehat Pesenam}

Gaya hidup sehat peserta senam aerobik di Pusat Kebugaran Ciktam Studio Bengkulu merupakan suatu kegiatan atau aktivitas yang dilakukan secara terus menerus untuk memenuhi kebutuhan dan memperoleh fisik yang bugar. Melalui aktivitas senam aerobik dipercaya akan dapat membantu meningkatkan kebugaran fisik dan kesehatan. Bagi peminatnya senam aerobik menjadi kegiatan yang dapat memenuhi kebutuhan jasmani peserta senam aerobik, karena kebutuhan jasmani itu sangat penting bagi tubuh. Senam aerobik juga menjadi olahraga rekreasi bagi peminatnya, karena dapat membuat para pesenam menjadi segar kembali dari pekerjaan yang dihadapinya baik saat bekerja maupun di rumah. Senam aerobik itu sendiri merupakan tempat berinteraksi dan sebagai sumber informasi bagi peserta senam aerobik. Selain itu perempuan pesenam aerobik ini memanfaatkan waktu luang yang dimilikinya sebagai wadah untuk mengekspresikan dirinya sebagai usaha untuk mencapai gaya hidup yang diinginkannya.

\section{Pengetahuan Peserta Senam Akan Manfaat Senam Aerobik}

Menurut Kamus Besar Bahasa Indonesia (KBBI) pengetahuan adalah suatu yang diketahui, pengetahuan juga diartikan sebagai segala sesuatu yang diketahui atau disadari oleh orang lain. Bagi peserta senam pengetahuan akan senam aerobik sebagai pola hidup sehat merupakan pengetahuan didapatkan para pesenam melalui indra penglihatan (mata) dan indra pendengaran (telinga). Dari indra pendengaran dahulunya pesenam mendengar bahwa adanya komunitas senam aerobik yang dapat membantu tubuh menjadi bugar, 
senam aerobik itu sendiri merupakan aktivitas gerak yang diiringi dengan irama musik. Setelah mendengar banyak hal tentang senam aerobik ini, pesenam melihat langsung benar adanya komunitas senam aerobik yang saat itu baru saja dibuka yaitu Pusat Kebugaran Ciktam Studio hingga akhirnya dorongan dari suami yang menganjurkan untuk mengikuti aktifitas senam aerobik agar tubuh semakin sehat dan bugar membuat perempuan peserta senam aerobik tertarik untuk bergabung pada komunitas itu.

5. Senam Memperoleh Fisik Yang Bugar

Kebugaran jasmani merupakan hal yang paling didambakan semua orang dalam memperoleh fisik yang bugar, pengalaman berperan penting dalam memperoleh fisik yang bugar. Seseorang yang memiliki tubuh bugar dan sehat perlu memiliki gaya hidup yang mendorong tumbuhnya kebugaran. Kebiasaan akan hidup sehat dengan aktif bergerak setiap hari dengan melakukan berbagai kegiatan dan aktifitas fisik yang teratur, akan dapat membantu tubuh menjadi bugar.

6. Senam Menurunkan Berat Badan

Berat badan ideal merupakan dambaan sebagian besar perempuan pesenam aerobik, sehingga tak heran jika orang berlomba-lomba untuk mendapatkan berat badan ideal. Mempunyai berat badan ideal tentunya penting dalam upaya mempertahankan kesehatan. Berat badan yang ideal adalah salah satu tujuannya pesenam tergabung ke komunitas senam aerobik Pusat Kebugaran Ciktam Studio. Selain untuk kebugaran tubuh senam aerobik bagi pesenam merupakan kegiatan atau aktivitas senam aerobik yang dipercaya mampu membuat berat badan menurun hingga $5 \mathrm{~kg}$ dalam 1 bulan, sehingga peserta senam semakin yakin bahwa senam aerobik memang mampu membakar lemak jahat dan dapat menurunkan berat badan melalui gerakan-gerakan senam yang diiringi oleh musik tersebut. Aerobik merupakan salah satu olahraga untuk membakar lemak jika dilakukan dengan rutin, karena pada saat senam aerobik berlangsung semua bagian tubuh ikut bergerak hingga akhirnya lemak pun ikut terbakar. Bagi perempuan peserta senam aerobik bahwa penurunan berat badan akan dirasakan saat seseorang rutin mengikuti senam aerobik

\section{Diet Sehat Perempuan Pesenam}

Diet merupakan suatu cara dalam membatasi porsi makan dengan memilih makanan dan minuman, karena diet yang sehat adalah kebiasaan yang dimulai dari memakan makanan bergizi seimbang. Banyak yang beranggapan bahwa diet berarti memaksakan kehendak agar tidak memakan makanan yang mengandung lemak dan 
karbohidrat yang tinggi. Sebenarnya menurut peserta senam aerobik, itu merupakan suatu hal yang salah, karena menurut mereka kita bisa makan apa yang kita mau atau apa yang kita inginkan tetapi kita harus dapat mengontrol apa yang harus kita makan tersebut, dan kita juga harus memperhatikan apa yang seharusnya kita konsumsi serta apa yang seharusnya tidak kita konsumsi berlebihan. Karena apapun yang dikonsumsi berlebihan, sangat tidak baik untuk kesehatan tubuh, jadi dalam menerapkan pola hidup sehat itu berarti mengurangi porsi makan, bukan tidak makan sama sekali atau memaksakan kehendak agar tidak makan.

\section{Atribut Pesenam Aerobik (Fashionable)}

Atribut senam merupakan perlengkapan senam yang dibutuhkan bagi peserta senam aerobik seperti pakaian berupa baju khusus senam, celana senam dan sepatu untuk para pesenam. Peserta senam aerobik pastinya menggunakan perlengkapan senam seperti baju senam, celana senam dan sepatu senam. Pesenam beranggap bahwa fashion (pakaian) merupakan hal yang wajib dikenakan bagi pesenam karena fashion akan membuat kepercayaan diri semakin tinggi, apa yang dikenakan atau apa yang dipakai akan membuat kebanggan tersendiri bagi mereka.

\section{Gerak Yang Diperagakan Instruktur}

Secara umum, gerak merupakan suatu perubahan. Dalam arti klasik, gerakan mencakup semua bentuk perubahan dalam posisi. Sedangkan secara khusus, gerakan adalah perubahan lokasi dari benda-benda yang berhubungan satu sama lain. Proses (tindakan atau keadaan) perubahan tempat (posisi). Dengan demikian yang dimaksud gerak adalah perubahan tempat atau suatu benda terhadap titik acuan atau titik asal tertentu.

Menurut instruktur senam aerobik di Pusat Kebugaran Ciktam Studio bahwa gerakan merupakan hal yang paling penting dalam senam aerobik. Seorang instruktur senam memperagakan gerakan-gerakan senam melalui 2 (dua) jenis gerakan aerobik, yaitu yang pertama melalui gerakan aerobik upper body (badan bagian atas) yang meliputi gerakan dengan clap (bertepuk tangan), swim (mengayunkan tangan kanan dan kekiri), punching ( meninju), push (mendorong tangan kedepan atau keatas), reach and pull (meraih dan menarik tangan sebatas bahu), biceps (menarik lengan ke depan), butterfly (mendorong lengan ke depan dada), leteral raise (merentangkan lengan ke samping setinggi bahu). Gerakan-gerakan pada upper body (badan bagian atas) ini bertujuan untuk meningkatkan sirkulasi darah diseluruh tubuh dan dapat meredakan nyeri 
karena gerakan-gerakan ini akan dapat memperlancar aliran oksigen ke seluruh tubuh menjadi lancar.

Kedua gerakan lower body (badan bagian bawah) yaitu meliputi gerakan dengan plle (membuka kaki selebar bahu dan ditekuk sedikit), squat (membuka kaki paralel dan ditekuk), walking (berjalan), walking forward (berjalan maju kedepan), walking backward (berjalan mundur kebelakang), marching (jalan di tempat), run (berlari), v-step (langka segitiga kedepan membentuk huruf v), a-step (langka segitiga ke belakang membentuk huruf A), leng curl (menekuk kaki bergantian ke belakang), knee up (mengangkat kaki setinggi 90 derajat), twist (menggerakkan pinggul kekanan kekiri), step touch (langka kaki satu kali kekanan kiri), grapevines (melangkah kaki dua kali kekanan atau kekiri dengan menyilangkan kaki dibelakang), jumping jack (melompat dengan mendorong kaki kekanan dan kekiri secara bersamaan), flick kick (menendang kaki ke depan secara bergantian kanan dan kiri), step/slide (menggeserkan kaki kekanan dan kekiri), touch back (mendorong kaki ke belakang bergantian kanan dan kiri), punny (meloncat dengan satu kaki diangkat bergantian kaki kanan dan kaki kiri), basic step (melangkah kaki satu langkah kedepan).

\section{KESIMPULAN}

Berdasarkan hasil penelitian dan temuan di lapangan bahwa gaya hidup perempuan komunitas senam aerobik diekspresikan melalui aktivitas, minat dan opini. Aktifitasnya dilihat melalui aktivitasnya di dalam rumah dan di luar rumah, sedangkan minatnya bergabung pada komunitas senam aerobik, dan opininya yaitu pesenam merupakan perempuan modern. Sedangkan gaya hidup sehat perempuan peserta senam aerobik ini seimbang antara pola makan, kebiasaan rutin berolahraga dan pengaturan waktu istirahat yang cukup guna mendapatkan fisik yang sehat. pengetahuan peserta senam akan manfaat senam aerobik seperti senam memperoleh fisik yang bugar, senam menurunkan berat badan, diet sehat perempuan pesenam, atribut pesenam aerobik (fashionable) dan gerakan yang diperagakan oleh instruktur senam.

\section{DAFTAR PUSTAKA}

Aji. 2015. Stratifikasi Sosial Dan Kesadaran Kelas. Dalam Jurnal Sosial Dan Budaya Syar'i. Vol. 2, No.1 
Arbaini, Yonyanis. 2017. Gaya Hidup Shopaholic Pada Mahasiswa. Dalam Jurnal Jom Fisip Vol. 4, No.1

Candrawati Dkk. 2016. Senam Aerobik Meningkatkan Daya Tahan Antung Paru Dan Fleksibiliti. Dalam Jurnal Kedokteran Brawijaya Vol. 29, No. 1

Hendariningrum, Susilo. 2008. Fashion Dan Gaya Hidup : Identitas Dan Komunikasi. Dalam Jurnal Ilmu Komunikasi, Vol. 6, No. 2

Khairunnisa, Sabrian, Safri. 2015. Hubungan Gaya Hidup Dengan Prestasi Akademik Mahasiswa Keperawatan Universitas Riau Dalam Jurnal Jom Vol. 2, No. 2

Kusmaedi. 2012. Pembelajaran Gaya Hidup Sehat Menuju Tingkat Sehat Prima Terpadu Sepanjang Hayat. Dalam Jurnal Cakrawala Pendidikan. Xxxi, No. 2

Paramitha. 2014. Pengaruh Gaya Hidup Sehat Untuk Mengatasi Turnover Intentions Yang Terjadi Di Akuntan Publik. Dalam Jurnal Akuntansi Bisnis, Vol. Xiii, No. 25

Prastika. 2019. Hubungan Dukungan Suami Dan Gaya Hidup Dengan Kualitas Hidup Akseptor Kb Iud. Skripsi Program Studi Keperawatan Fakultas Keperawatan Universitas Airlangga Surabaya

Purwanto. 2011. Dampak Senam Aerobik Terhadap Daya Tahan Tubuh Dan Penyakit. Dalam Jurnal Media Ilmu Keolahragaan Indonesia. Vol. 1. Edisi 1.

Ramadani. 2018. Gaya Hidup Remaja Putri Yang Berkarir Sebagai Biduan di Smk Yos Sudarso Sidarejo Kabupaten Cilalap. Skripsi Jurusan Bimbingan Konseling Islam Fakultas Dakwah Institut Agama Islam Negeri Purwokerto

Ramadhani. 2019. Pengaruh Latihan Aerobik Dan Senam Aerobik Low Impact Terhadap Peningkatan Vo2 Maks Pada Siswi Sma Mta Surakarta. Skripsi Fisioterapi Fakultas Ilmu Kesehatan

Saebani, Jamaludin, 2015. Sosiologi Perkotaan Memahami Masyarakat Kota Dan Problem Matikanya. Bandung: Pustaka Setia

Triwijayati, Pradipta. 2018. Kelas Sosial Vs Pendapatan Eksplorasi Faktor Penentu Pembelian Consumen Goods Dan Jasa. Dalam Jurnal Ekonomi Vol. XXIII, NO. 02 